\title{
Imaging of Melting and Crystallization of Poly(ethylene oxide) in Real-Time by Hot-Stage Atomic Force Microscopy
}

\author{
R. Pearce and G. J . Vancso* \\ Faculty of Chemical Technology, University of Twente, P.O. Box 217, \\ $7500 \mathrm{AE}$, Enschede, The Netherlands
}

Received April 4, 1997; Revised Manuscript Received J une 14, $1997^{\circledR}$

\begin{abstract}
Crystallization and melting in poly(ethylene oxide) are followed in real-time using hotstage atomic force microscopy (AFM). Hedritic morphology is observed at various stages of development. Lamellar growth rates are estimated and found to agree with values obtained by conventional optical microscopy. The presence of a depletion zone is detected at the crystal/melt interface.
\end{abstract}

\section{Introduction}

The study of polymer morphology has, of necessity, followed a path parallel to that of technical developments in the area of materials structure elucidation. With the development of new staining and etching techniques, the use of electron microscopy has yielded remarkable insight into the morphological details of melt-crystallized polymers. Bassett, Vaughan, and coworkers have identified three basic steps in the development of crystalline morphology. ${ }^{1-3}$ The first step involves the formation of dominant lamellae, which form a three-dimensional "skel eton" by splaying apart. In a subsequent step, subsidiary lamellae fill-in the structure between the dominant lamellae. Finally, material which is precluded from crystallizing at the crystallization temperature does so upon cooling. There is a concomitant fractionation, since the dominant lamellae will tend to contain the longest molecules. The concept of fractionation upon crystallization has also been investigated by Wunderlich, Cheng, and co-workers. ${ }^{4-6}$ The origins of the splaying which is evident in the early stages of spherulitic growth, when the crystallizing entity can be more appropriately described as a hedrite, ${ }^{7}$ remain an unresolved issue. Two possible mechanisms are the compression of cilia (portions of molecules protruding on the faces of adjacent lamellae) and reptation forces. ${ }^{2,8}$

Of the instrumentation devel oped in the past 10-20 years, the most promising in the context of polymer morphological investigations has been the family of microscopic techniques collectively referred to as scanning probe microscopy (SPM). Chief among these is the atomic force microscope (AFM) ${ }^{9}$ In recent years there has been a rapid increase in the number of literature reports demonstrating the power of the AFM. In some instances it has proven possible to image individual polymer chains ${ }^{10-12}$ and even methyl or methylene group substituents. ${ }^{13-18}$ In addition to excellent resolution, AFM has the added benefit of simplicity in terms of operation and sample preparation. Noteworthy is the fact that for most applications the need for procedures such as microtoming or gold coating is obviated.

During the so-called height imaging of morphological features at the sample surface, a feedback loop of the instrument ensures that the distance between the probe and the sample is kept constant to within atomic dimensions. Thus the tip "follows" the sample surface,

\footnotetext{
${ }^{\otimes}$ Abstract published in AdvanceACS Abstracts, August 1, 1997.
}

and true three-dimensional images are created by capturing the $x, y$ and $z(x, y)$ coordinates of structural features. The ability of AFM to produce these quantitative images is unique among all microscopic techniques.

Despite the many insights into polymer morphology gleaned by using electron microscopy and AFM, these techniques have hitherto proven useful mostly for static measurements. In the case of semicrystall ine polymers, this typically necessitates the growth of polymer crystals (single crystals or larger-scale structures) followed by quenching and, in a subsequent step, transfer to the electron microscope or AFM for examination. Most dynamic studies of morphological development have been performed using polarized optical microscopy, with its limited resolution. Quite recently a report has appeared presenting results on time-dependent morphological changes in silver films at temperatures between 30 and $100{ }^{\circ} \mathrm{C}$ as observed by AFM.19 Previously, results have been obtained demonstrating the ability of AFM to follow the real-time dynamics of clotting of blood protein ${ }^{20}$ and the solid-state photodimerization of cinnamic acid. ${ }^{21}$ Most recently, McMaster and co-workers have succeeded in following the growth of a poly( $\beta$-hydroxybutyrate-co-hydroxyvalerate) spherulite at room temperature by tapping-mode AF M. ${ }^{22}$ Some recent applications of SPM methods to dynamic studies have been reviewed. ${ }^{23}$ In the context of polymer morphology most published results have been obtained at ambient temperature; however, a study has appeared describing changes in a liquid-crystalline polymer as it is cooled from room temperature to $268 \mathrm{~K} .{ }^{24} \mathrm{Also}$, an estimate of the linear expansion coefficient of poly(tetrafluoroethylene) has been obtained by placing the AFM scan head in a refrigerator. ${ }^{25} \mathrm{~F}$ or measurements requiring extremely low temperatures, a description of an instrument capable of operation at cryogenic temperatures has been published. ${ }^{26}$

The present paper summarizes our results pertaining to the monitoring of melting and crystal lization in poly(ethylene oxide), PEO, in real-time, by AFM. Previously published images of polymer morphology evolution obtained in real-time at el evated temperatures have generally been restricted to optical microscopic measurements, with their inherently lower resolution. For the measurements described herein, a small heating stage was constructed, based on one which has been described in the literature. ${ }^{27}$ PEO was chosen for this study because of it's low melting point $\left(\mathrm{T}_{\mathrm{m}}{ }^{\circ}=69^{\circ} \mathrm{C}\right)$ and because it has been shown to exhibit a wealth of morphological forms. ${ }^{28-30}$ 
(A)

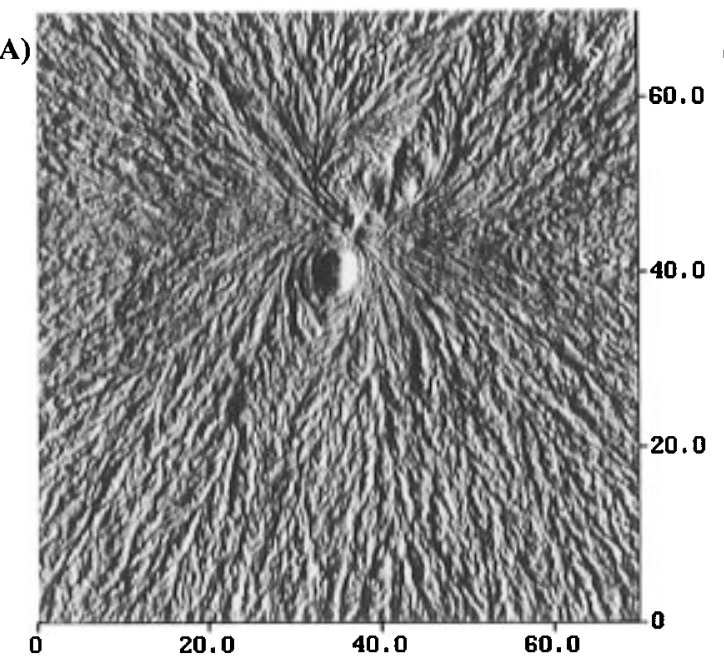

(B)

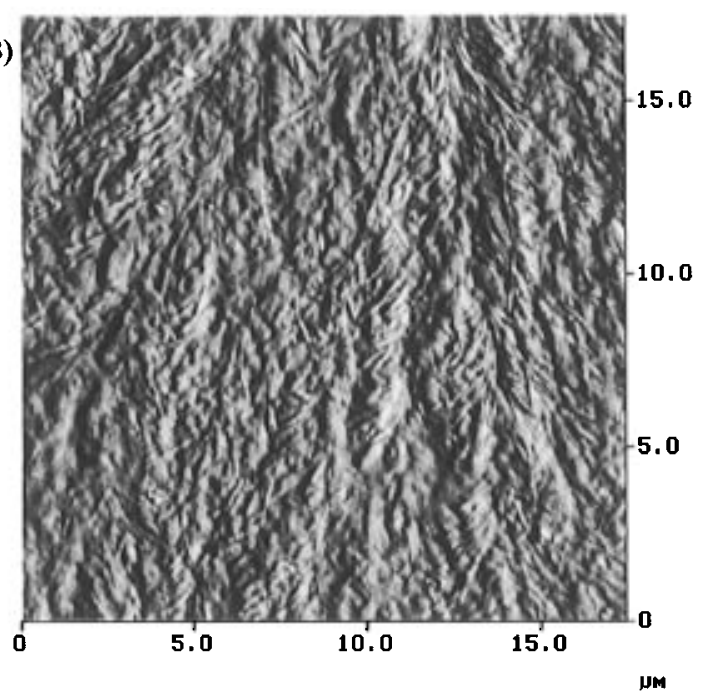

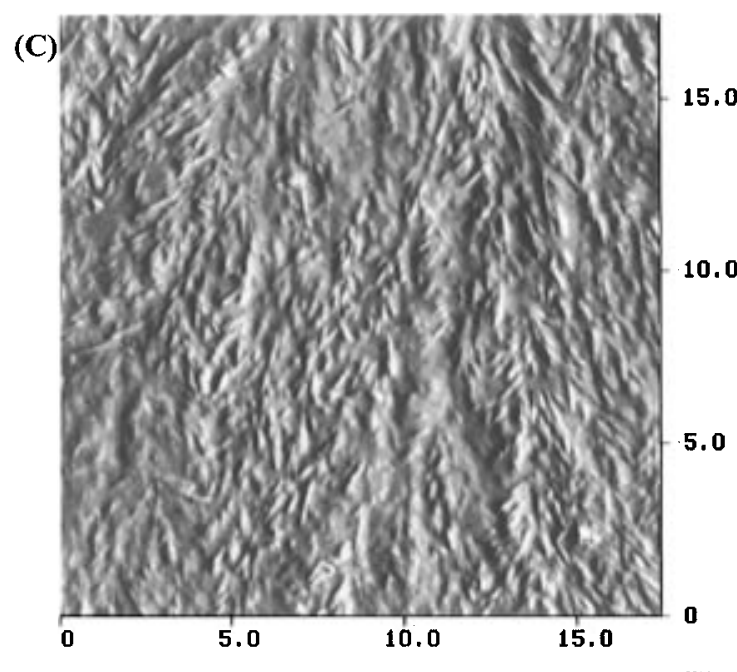

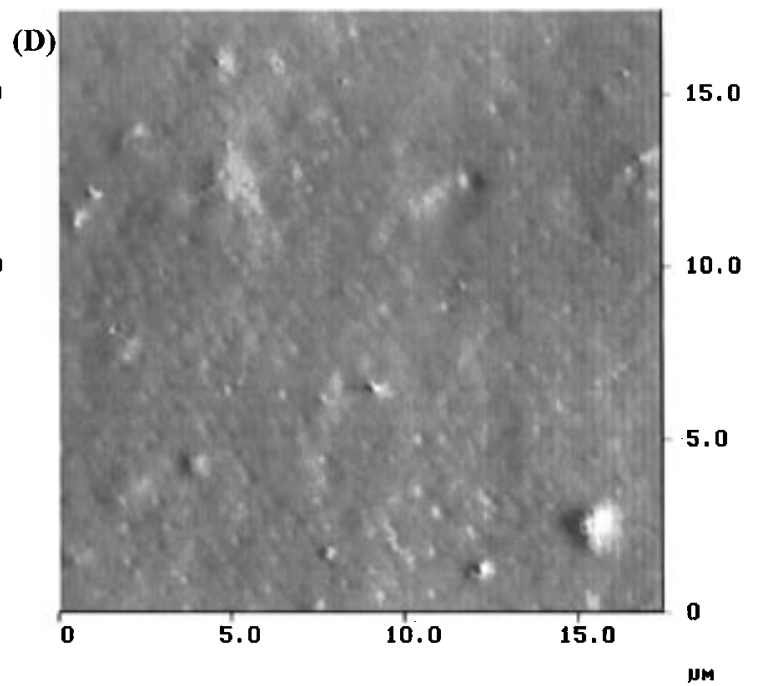

Figure 1. Deflection images of a PEO spherulite at (A) $50^{\circ} \mathrm{C}$ and (B-D) $63^{\circ} \mathrm{C}$. The total elapsed time between parts $\mathrm{B}$ and $\mathrm{D}$ is $10 \mathrm{~min}$.

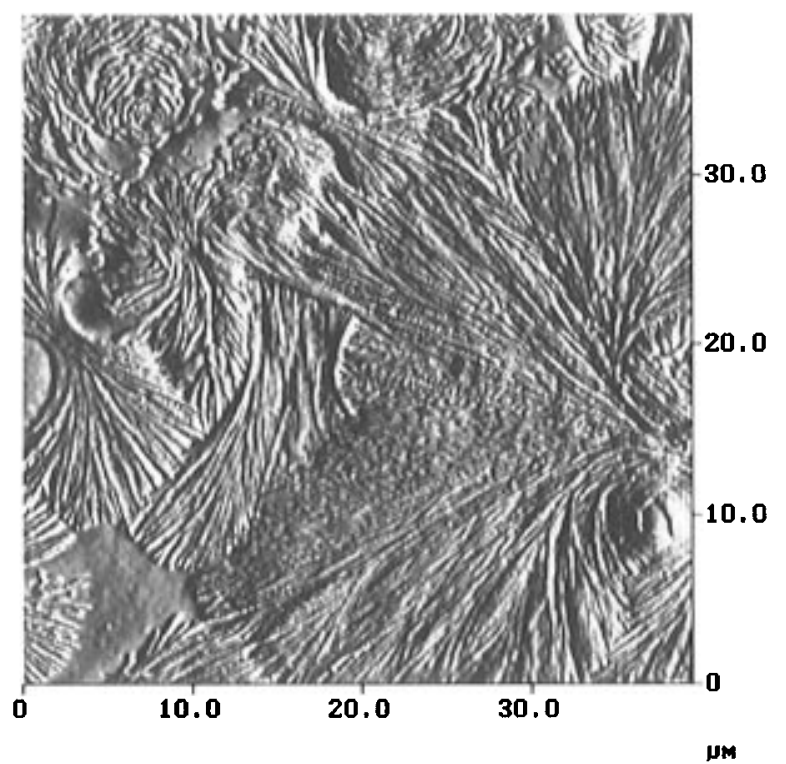

Figure 2. Deflection image of PEO hedrites after 20 min of growth at $57^{\circ} \mathrm{C}$.

\section{Experimental Section}

Poly(ethylene oxide) was obtained from Aldrich (MW 2000000 ) and was precipitated from chloroform into hexanes prior to use. Samples were prepared by casting from dilute (ca. $2 \%$ ) chloroform solutions.

The heating stage used was a variation of a previously published design.27 A thin rectangular Kapton heating pad ( $2 \mathrm{~cm} \times 1 \mathrm{~cm} \times 200 \mu \mathrm{m}$, supplied by Cole-Parmer)) was fixed onto a $1 \mathrm{~cm}$ AFM sample disk. This was then placed onto a second disk on which had been placed 3 small drops of epoxy, in such a way that a thin (ca. $1 \mathrm{~mm}$ ) gap was present to ensure air flow and prevent excessive heating of the AFM piezo. A copper electrode was constructed from thin $\mathrm{Cu}$ foil $(25 \mu \mathrm{m})$, as described in ref 27 . The PEO sample was cast directly onto the copper electrode. Temperature was varied by using a simple dc power supply (Voltcraft Model 2256). A small K-type thermocouple was used to measure temperature, which was also checked using a compound having a known melting point (benzophenone, 99\%).

Atomic force microscopy was carried out on a Digital Instruments Nanoscope III, using a J -scanner and NanoProbe $\mathrm{Si}_{3} \mathrm{~N}_{4}$ tips (nominal $\mathrm{k}=0.38 \mathrm{~N} / \mathrm{m}$ ). Measurements were carried out in contact mode, always using the smallest possible setpoint so as to minimize interaction forces between tip and sample.

Optical microscopic measurements of crystallization kinetics were carried out on an Olympus BX60 polarizing microscope equipped with a Mettler FP80 hotstage. Samples of PEO, in the form of thin films, were heated to $75^{\circ} \mathrm{C}$, held at this temperature for $1 \mathrm{~min}$, and then quenched to the desired crystallization temperature. Spherulites were photographed between crossed polars at regular intervals and radii measured and plotted as a function of time to yield the radial growth rate. 

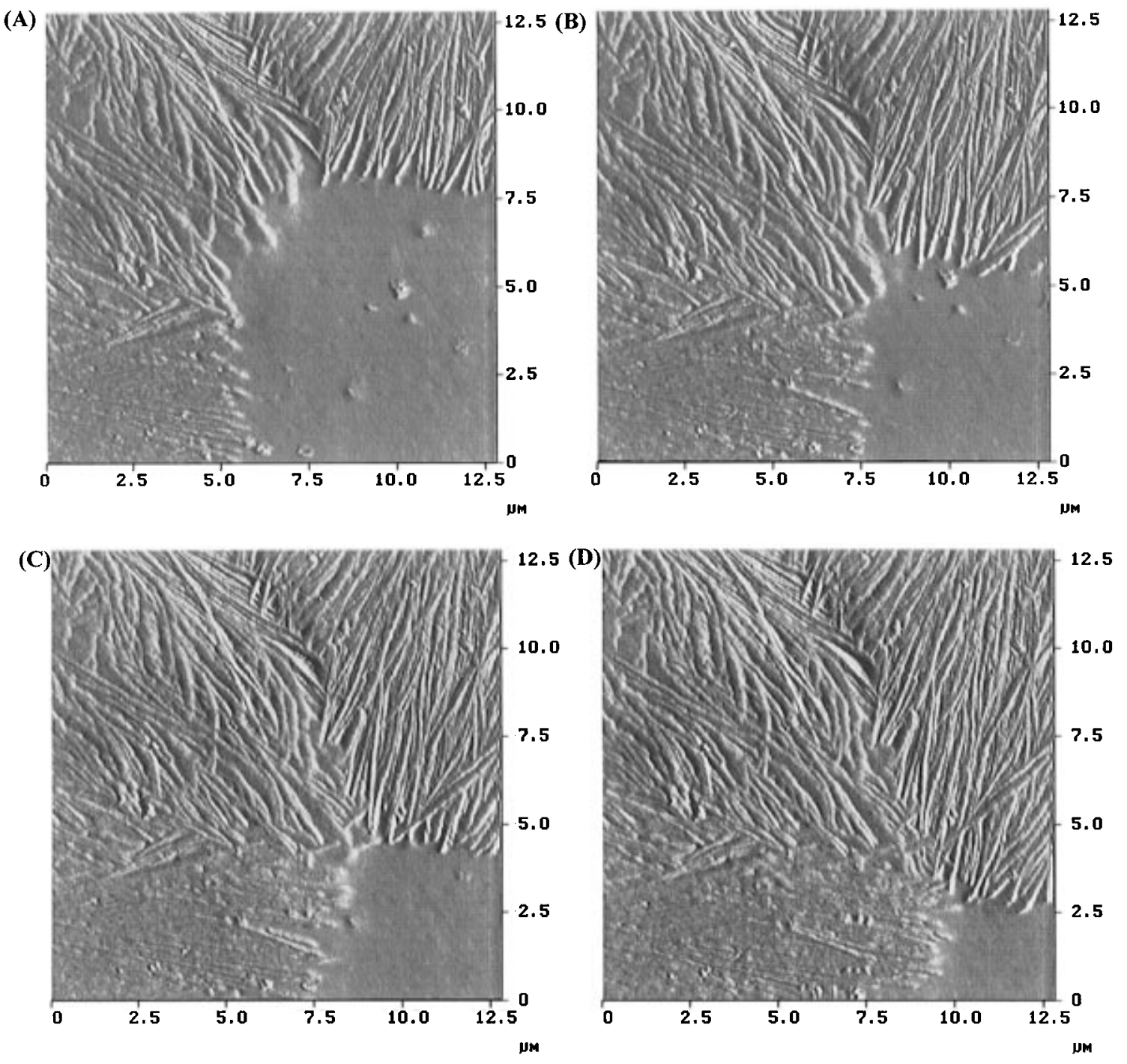

Figure 3. Deflection images of PEO spherulites growing at $57^{\circ} \mathrm{C}$. The elapsed time between successive images is 3 min.

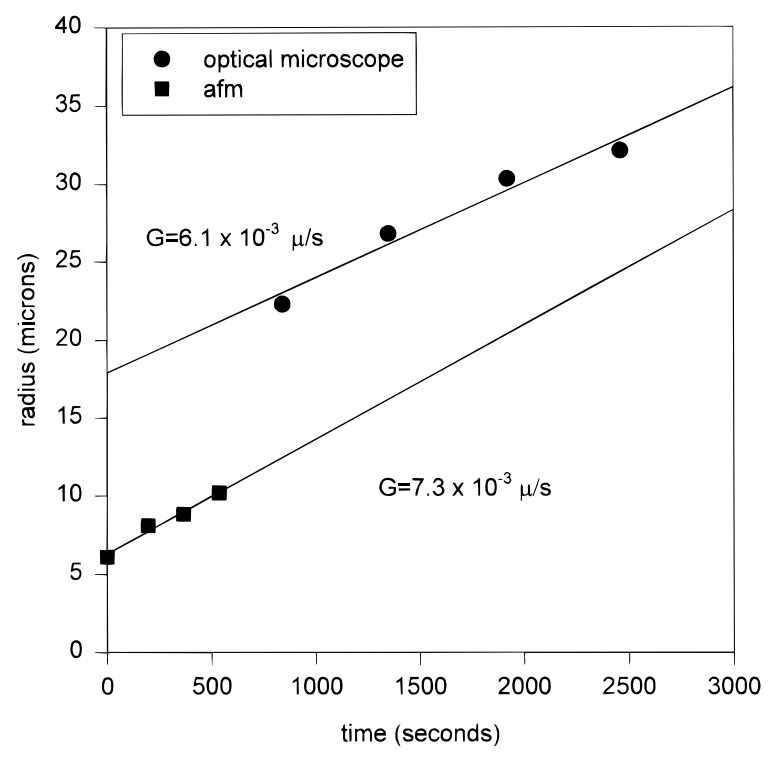

Figure 4. Lamellar growth rates at $57^{\circ} \mathrm{C}$ measured by AFM

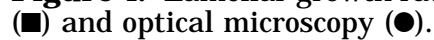

\section{Results and Discussion}

Melting of PEO. With the use of the simple heating stage described, it was possible to observe the melting of crystallized PEO samples. An example is given in
Figure 1, which shows a series of images acquired in deflection mode. In Figure $1 \mathrm{~A}$ is shown a PEO spherulite grown at a temperature of $52^{\circ} \mathrm{C}$. In the center of the image is seen the typical asymmetric structure which is characteristic of the early stages of spherulitic development, when the morphology is more accurately described as hedritic. ${ }^{7}$ The stack of lamellae at the core of the hedrite splay out, eventually imparting an overall sphericity to the structure. The image in Figure $1 \mathrm{~A}$ was acquired at $50{ }^{\circ} \mathrm{C}$, before the onset of any discernible melting.

The image in Figure 1B shows a section of the same spherulite as in Figure $1 \mathrm{~A}$ but acquired after approximately $1 \mathrm{~min}$ at $63^{\circ} \mathrm{C}$. It can be seen that melting has begun. The molten material corresponds to the featureless patches which are dispersed throughout the image. Interestingly, some of the internal lamellar structure has been revealed, so that partial melting is akin to a thermal etching. This process continues in Figure $1 C$, which shows the presence of both longer dominant lamellae and shorter subsidiary lamellae. For example, at the top of the image, approximately onethird of the distance from the right-hand corner, a dominant lamella can be seen which extends downward toward the left-hand corner. Along its length there are molten regions as well. In melt-crystallized polymer samples, there is also a third fraction comprising material which is incapable of crystallizing at the 


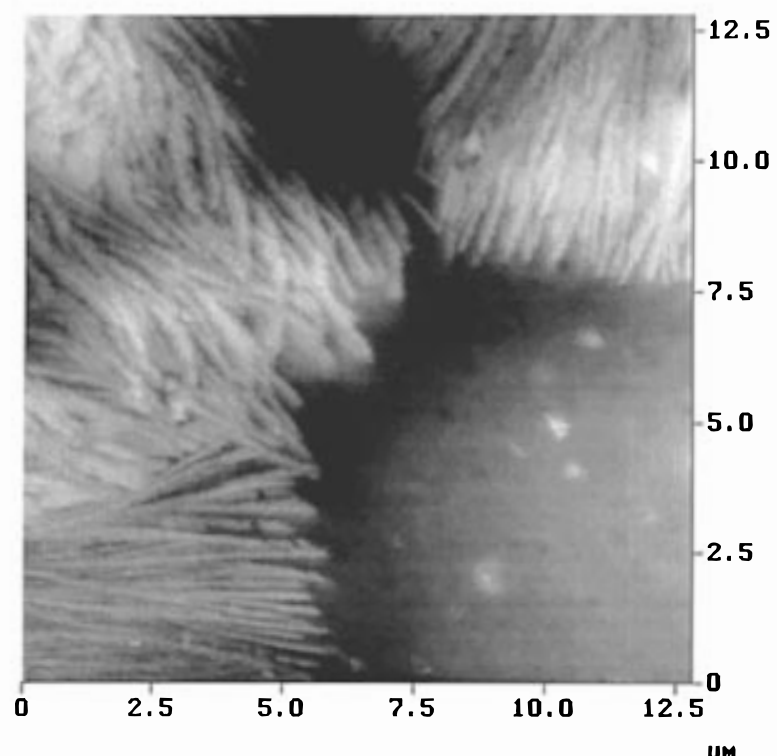

(A)

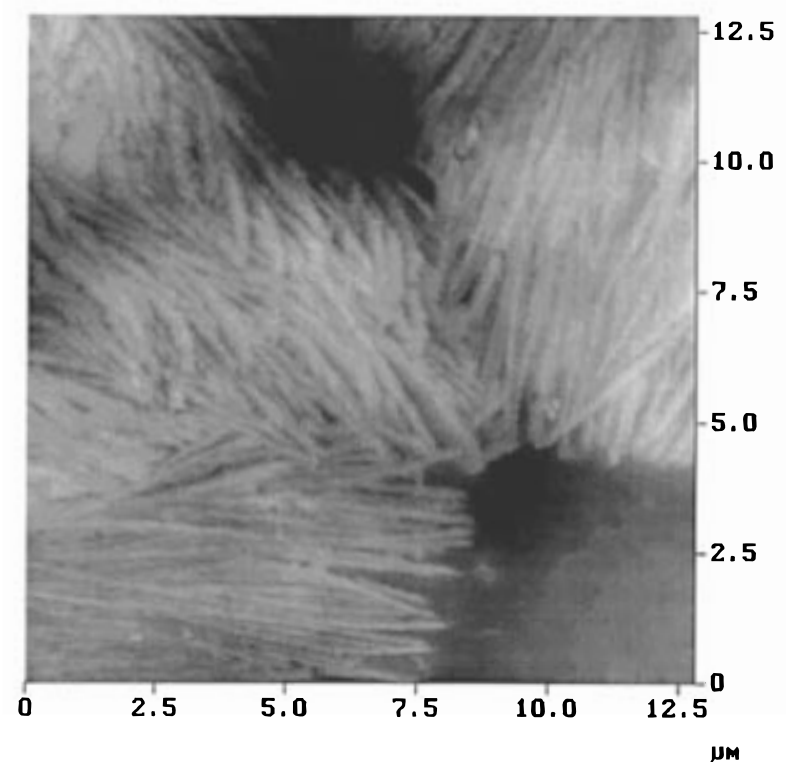

(C)

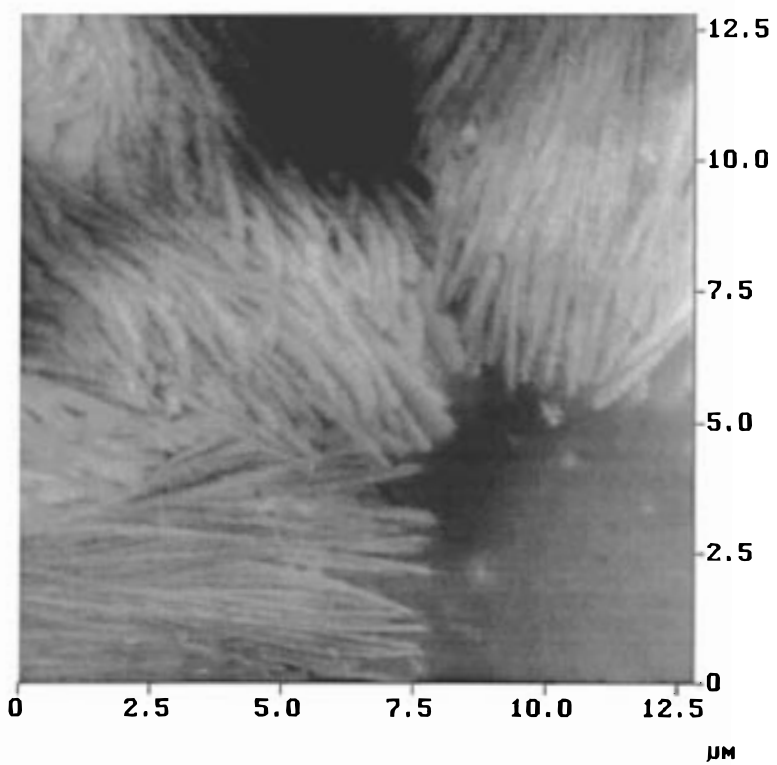

(B)

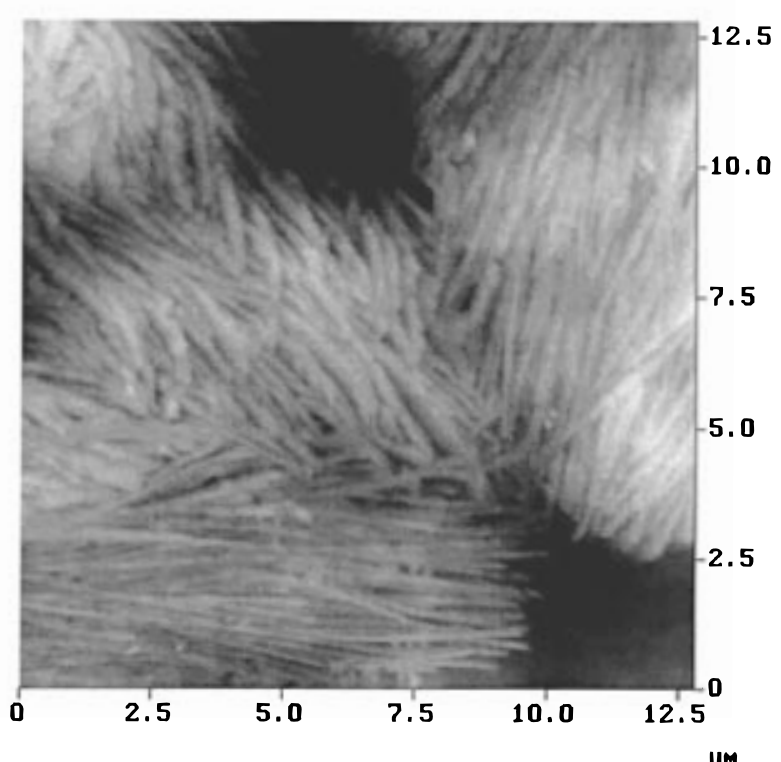

(D)

Figure 5. AFM height images corresponding to deflection images in Figure 3. The vertical scale is $800 \mathrm{~nm}$ (dark to bright).

nominal crystallization temperature but can do so upon cooling. 2,8 This material will be among the first to melt.

The process of melting was found to be slow at $63^{\circ} \mathrm{C}$, requiring approximately $10 \mathrm{~min}$ for all traces of crystalline structure to disappear (Figure 1D). It was found possible to scan the completely molten sample without the cantilever tip "sticking".

Crystallization of PEO. Following complete melting, the temperature of the sample was decreased to 57 ${ }^{\circ} \mathrm{C}$. At this small undercooling the crystallization rate is low enough that the changes in morphology can be easily observed by AFM.

In Figure 2 can be seen a deflection image obtained after approximately $20 \mathrm{~min}$ at $57{ }^{\circ} \mathrm{C}$. As reported by Allen and Mandelkern, ${ }^{28}$ this temperature is above that of the lower limit for hedritic development in PEO. This is consistent with the morphology in Figure 2, which shows hedrites in various stages of development. On the left-hand side is an example of the splaying structure typical of hedritic growth (vide supra). The central eyelets have not yet closed, and spherical symmetry has not yet been attained.

This projection corresponds to an edge-on view with respect to the lamellae. On the right-hand side can be seen a larger structure which has progressed to the later stage of growth, where the overall morphology is more properly termed spherulitic. On the righter-most edge one of the eyel ets is seen to have closed. In the upper left-hand corner of the image is visible a structure corresponding to a slightly different projection, between edge-on and flat-on, yielding a "flower petals" arrangement. 2

The use of AFM to follow kinetics can be illustrated by the series of deflection images shown in Figure 3. These correspond to the growth fronts of at least three separate spherulites. Thelamellae from two spherulites can be seen extending down from the upper right-hand corner and across from the lower left-hand corner. In between these there is a third spherulite whose lamellae exhibit a slightly different projection (closer to flat-on). 

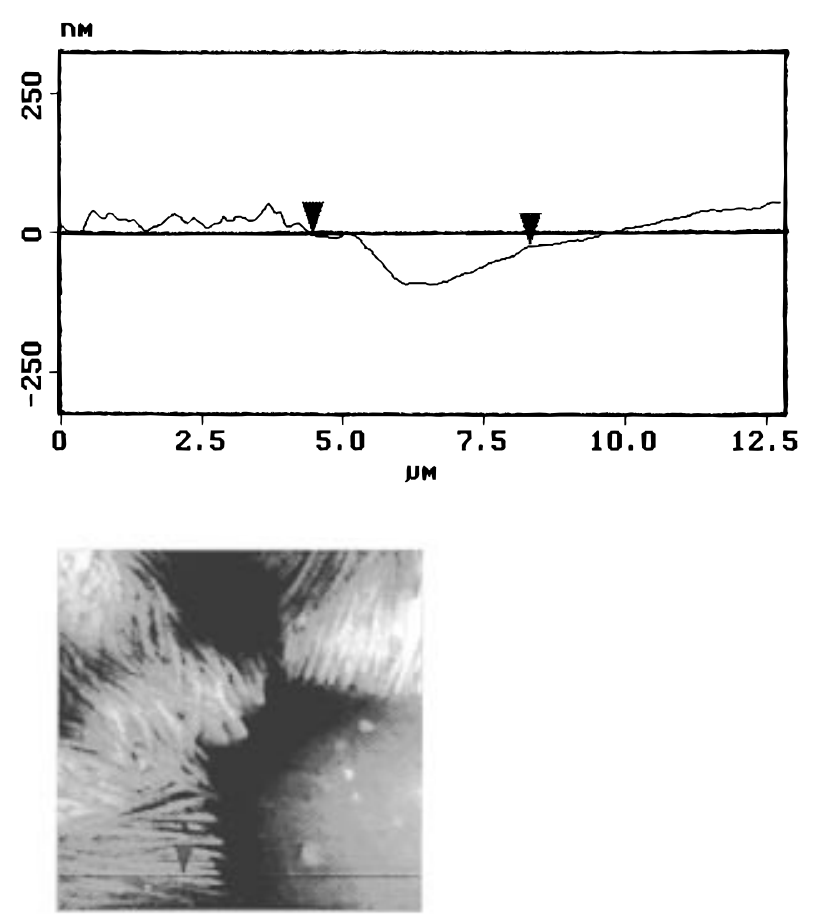

Figure 6. Height profile across the crystalline/melt interface for a growing PEO spherulite.

Successive images in the figure were obtained at $3 \mathrm{~min}$ intervals. The progression of the growth fronts is evident. In order to quantify the crystallization rate, attention was focussed on lamellae growing in a horizontal direction, perpendicular to the scan direction. This was done in order to circumvent errors due to the finite time required to complete a scan (typically around $1 \mathrm{~min})$. When the length of a given lamella was measured by AFM as a function of time, the data shown in Figure 4 were obtained (see filled squares). For comparison the growth rate of spherulites was also measured by conventional optical mi croscopy (see filled circles in Figure 4). Despite some scatter in the data, there is good agreement between the slopes of the two straight lines, from which the linear growth rates are obtained. The AFM data have inherently lower precision since it is difficult to foll ow the growth of an object over very large distances by AFM. The kinetic results are also consistent with previously published data obtained by optical microscopy. ${ }^{31}$ While the AFM data in Figure 4 were obtained on a particular lamella, a careful examination of the images in Figure 3 reveals that in fact there is a slight spread in the rate of advancement of the lamellae. This observation demonstrates the advantage of AFM over conventional optical microscopy, which yields only an average value of individual lamellar growth rates.

The possibility of cantilever-tip-induced nucleation was considered. However, in the crystallization experiments it was found possible to scan molten amorphous regions, after the onset of crystallization in other areas of the sample, without observing any crystallization. Furthermore, the agreement in kinetics between optical microscopy and AFM tends to support the idea that the effect of the cantilever tip was purely passive in nature.

The ability of AFM to yield real-time height information is a distinct advantage over electron microscopy. In Figure 5 are shown the four height images corre sponding to the deflection images of Figure 3 . The former have poorer lateral resolution but permit a characterization of actual height. The presence of a depletion layer in front of the growing crystalline lamellae is evident and confirms results obtained on a poly ( $\beta$-hydroxybutyrate-co-hydroxyval erate) spherulite. ${ }^{32}$ In Figure 6 is shown a surface profile which better illustrates the phenomenon. As molten polymer becomes incorporated into the growing lamellae a certain depletion occurs. Clearly, an amount of material must remain in the depletion zone for crystallization to progress. Intuitively this amount should depend on temperature, which affects the rate of advancement of the growth front and the melt transport processes as well as the difference in densities between the two phases. When two growing spherulites approach each other within a distance on the order of the depletion zone (in the example given approximately $2 \mu \mathrm{m}$ ), the net result will be a slight depression in the area of impingement. This effect can be seen, for example, in Figure $5 \mathrm{C}$ as a dark area along the diagonal connecting the upper and middle spherulites.

\section{Summary and Conclusions}

This paper has summarized the results obtained in the AFM study of melting and crystallization in PEO. For the first time it has been shown to be possible to follow both processes in real-time by using a simple heating stage apparatus. The kinetics of lamellar growth were monitored and found to agree with those obtained by conventional optical microscopy. The presence of a depletion layer was detected at the crystal/ melt interface. This is rationalized in terms of transport processes in the molten phase.

Acknowledgment. The authors are grateful to the University of Twente for financial support and to Drs. D. L. Trifonova (University of Twente) and M. J . Miles (University of Bristol) for helpful discussions.

\section{References and Notes}

(1) Vaughan, A. S.; Bassett, D. C. In Comprehensive Polymer Science, Vol. 2; Booth, C., Price, C., Eds.; Pergamon Press: Oxford, U.K., 1989.

(2) Bassett, D. C.; Vaughan, A. S. Polymer 1985, 26, 717.

(3) Bassett, D. C. Philos. Trans. R. Soc. London A 1994, 348, 29.

(4) Cheng, S. Z. D.; Bu, H. S.; Wunderlich, B. J . Polym. Sci., Polym. Phys. Ed. 1988, 26, 1947.

(5) Cheng, S. Z. D.; Barley, J . S.; Von Meerwell, E. D. J . Polym. Sci., Polym. Phys. Ed. 1991, 29, 515.

(6) Cheng, S. Z. D.; Bu, H. S.; Wunderlich, B. Polymer 1988, 29, 579.

(7) Geil, P. H. In Polymer Single Crystals; Wiley Scientific: London, 1963.

(8) Vaughan, A. S. Sci. Prog. Oxford 1992, 76, 1.

(9) Binnig, G.; Quate, C. F.; Gerber, C. H. Phys. Rev. Lett. 1986 $56,930$.

(10) Hansma, H.; Motamedi, F.; Smith, P.; Hansma, P.; Wittman, J. C. Polymer 1992, 33, 647.

(11) Magonov, S. N.; Bar, G.; Cantow, H.-J .; Bauer, H. D.; Müller, I.; Schwoerer, M. Polym. Bull. 1991, 26, 223.

(12) Magonov, S. N.; Qvarnström, K.; Elings, V.; Cantow, H.-J . Polym. Bull. 1991, 25, 689.

(13) Lotz, B.;Wittman, J . C.; Stocker, W.; Magonov, S. N.; Cantow, H.-J. Polym. Bull. 1991, 26, 209.

(14) Snétivy, D.; Guillet, J. E.; Vancso, G. J . Polymer 1994, 34, 429.

(15) Snétivy, D.; Vancso, G. J . Polymer 1994, 35, 461.

(16) Snétivy, D.; Vancso, G. J . Colloid Surf. A 1994, 87, 257.

(17) Snétivy, D.; Yang, H.; Glomm, B.; Vancso, G. J . J . Mater. Chem. 1994, 4, 55.

(18) Snétivy, D.; Vancso, G. J .; Rutledge, G. C. Macromolecules 1992, 25, 7037.

(19) Semin, D. J .; Lo, A.; Roark, S. E.; Skodje, R. T.; Rowken, K. L. J . Chem. Phys. 1996, 105, 5542. 
(20) Drake, B.; Prater, C. B.; Weisenhorn, A. L.; Gould, S. A. C.; Albrecht, T. R.; Quate, C. F.; Cannell, D. S.; Hansma, H. G.; Hansma, P. K. Science 1989, 243, 1586.

(21) Kaupp, G. Angew. Chem., Int. Ed. Engl. 1992, 31, 592.

(22) McMaster, T. J ;; Hobbs, J. K.; Barham, P. J .; Miles, M. J . Probe Microsc., in press.

(23) Roberts, C. J .; Davies, M. C.; Shakesheff, K. M.; Tendler, S. J. B.; Williams, P. M. Trends Polym. Sci. 1996, 4, 420.

(24) Magonov, S. N.; Elings, V.; Papkov, V. S. Polymer 1997, 38, 297.

(25) Förster, S.; Liu, G.; Vancso, G. J . Polym. Bull. 1996, 36, 471.

(26) Kirk, M. D.; Albrecht, T. R.; Quate, C. F. Rev. Sci. Instrum. 1988, 59, 833.

(27) Muševič, I.; Slak, G.; Blinc, R. Rev. Sci. Instrum. 1996, 67 (2), 2554
(28) Allen, R. C.; Mandelkern, L.J . Polym. Sci., Polym. Phys. Ed. 1982, 20, 1465.

(29) Kovacs, A. J .; Gonthier, A. Kolloid Z. Z. Polym. 1972, 250, 530.

(30) Kovacs, A. J .; Straube, C.; Gonthier, A. J . Polym. Sci., Polym. Symp. 1977, 59, 31.

(31) Barnes, W. J .; Luetzel, W. G.; Price, F. P. J . Phys. Chem. 1961, 65, 80.

(32) McMaster, T. J .; Williamson, R. L.; Hobbs, J .; Barham, P. J .; Miles, M. J . Polym. Prepr. (Am. Chem. Soc., Div. Polym. Chem.) 1996, 37 (2), 553.

MA970463Y 